\title{
Concurrent surgical approach for partial abnormal pulmonary venous connection with an intact interatrial septum and pulmonary sequestration in a 19-month-old female child
}

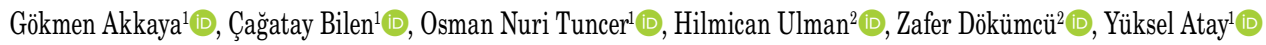 \\ ${ }^{1}$ Department of Cardiovascular Surgery, Ege University Faculty of Medicine, Izmir, Turkey \\ ${ }^{2}$ Department of Cardiac Surgery, Ege University Faculty of Medicine, Izmir, Turkey
}

Received: December 16, 2019 Accepted: January 20, 2020 Published online: March 20, 2020

\begin{abstract}
Both partial abnormal pulmonary venous connection with an intact interatrial septum and extralobar pulmonary sequestration are rare entities. In this article, we report a 19-month-old female patient who was in close follow-up since initially diagnosed when she was three months old. In admission, she was suffering from exertional dyspnea for the last two months. Surgical treatment was decided due to the increased ratio of pulmonary to systemic flow level. A tandem surgery was performed by cardiovascular and pediatric surgeons through a median sternotomy, respectively. The surgical process and intensive care period were uneventful.
\end{abstract}

Keywords: Intact interatrial septum, partial abnormal pulmonary venous connection, pulmonary sequestration.

Partial abnormal pulmonary venous connection (PAPVC) involves a dislocated blood flow from a few of the pulmonary veins returning to the right atrium instead of the left atrium. Usually, a single pulmonary vein is anomalous and right superior pulmonary vein drains into superior vena cava or right atrium. However, PAPVC has a frequency of $0.4-0.7 \%$ among all congenital heart diseases and is mostly associated with other cardiac anomalies, particularly atrial septal defects (ASDs). ${ }^{[1]}$ An anomalous pulmonary venous connection occurs in approximately $85 \%$ of patients with sinus venosus ASD and less often in ostium secundum ASD. Recently, some articles comprising a unique variant of PAPVC with an intact interatrial septum have been reported. ${ }^{[2-4]}$

On the other hand, pulmonary sequestration (PS) represents an accessory and nonfunctioning lung mass that has no communication with the usual tracheobronchial tree. Embryologically, it is composed of a bronchopulmonary foregut malformation with estimated incidence of 0.1 to $6.4 \% .^{[5]}$ Anatomically, it is divided into two major groups based on the relationship of the aberrant segmental lung tissue to the pleura as intralobar sequestration (ILS) and extralobar sequestration. Intralobar sequestration is not morphologically well separated from ordinary lung tissue and accounts for the majority of all sequestrations with a rate of $75-85 \%$. It is generally located in the right lower pulmonary lobe and may stay asymptomatic until the adolescence age even when infected. However, arterial flow of the sequestrated segment is commonly provided from thoracic aorta (74\%) and rarely from abdominal aorta (19\%); moreover, veins typically drain into inferior vena cava. ${ }^{[6]}$

In this article, we present a successful and concurrent surgical repair utilizing a multidisciplinary approach by pediatric surgeons in a symptomatic patient with the diagnosis of PAPVC with an intact atrial septum and right lower extralobar pulmonary lobe sequestration.

\section{CASE REPORT}

A 19-month-old female patient was in follow-up since postnatal period owing to right ear hypoplasia

Corresponding author: Gökmen Akkaya, MD. Ege Üniversitesi Tıp Fakültesi Kalp ve Damar Cerrahisi Anabilim Dal, 35100 Bornova, İzmir, Türkiye.

Tel: +90 232 - 3713565 e-mail: akkayagokmen@gmail.com

\section{Citation:}

Akkaya G, Bilen Ç, Tuncer ON, Ulman H, Dökümcü Z, Atay Y. Concurrent surgical approach for partial abnormal pulmonary venous connection with an intact interatrial septum and pulmonary sequestration in a 19-month-old female child. Cardiovasc Surg Int 2019;7(2):27-30. 
and facial deformities. In genetic examination, there was no identified disorder. However, transthoracic echocardiography (TTE) revealed that the right upper pulmonary vein was draining into superior vena cava, besides the interatrial septum was intact. Later on, when she was three months old, computed tomography demonstrated right lower lung lobe sequestration that supplied its arterial flow by an aberrant vessel arising from coeliac trunk (Figure 1a, b). Since then, she was kept in close follow-up with regular TTE examinations. During this period, a single therapy with spironolactone-hydrochlorothiazide with a dosage of $1.5 \mathrm{mg} / \mathrm{kg} /$ day was administered. A written informed consent was obtained from the parents of the patient.

Patient began to suffer from exertional dyspnea when she was 17 months old. There was no failure to thrive, the weight was $10.5 \mathrm{~kg}(25-50 \mathrm{p})$ and the height was $82 \mathrm{~cm}$ (75-90p). In the physical examination, auscultation was uneventful without loud P2 and electrocardiogram was in sinus rhythm. The conventional angiography confirmed the diagnosis and imaged the aberrant arterial flow towards the sequestrated lung mass. Moreover, the mean pulmonary arterial pressure was measured as $35 \mathrm{mmHg}$ (Figure 2).

As a result of these findings, the medical council decided on tandem surgery. The mediastinal access was achieved through median sternotomy. Following bicaval cannulation and antegrade cardioplegia administration, right atriotomy was performed and the dislocated pulmonary vein orifice was found. Aiming to steer this vein flow towards the left atrium, an atrial septectomy was constituted and a tunnel was constructed between the pulmonary venous orifice and newly created ASD via autologous pericardial patch. The whole process was completed in $70 \mathrm{~min}$ of $\mathrm{X}$-clamping time and $83 \mathrm{~min}$ of cardiopulmonary bypass time.

Thereafter, pediatric surgeons began to resect the sequestrated segment through the same incision conversely to the usual right thoracotomy approach. The arterial branches and the veins of the sequestrated
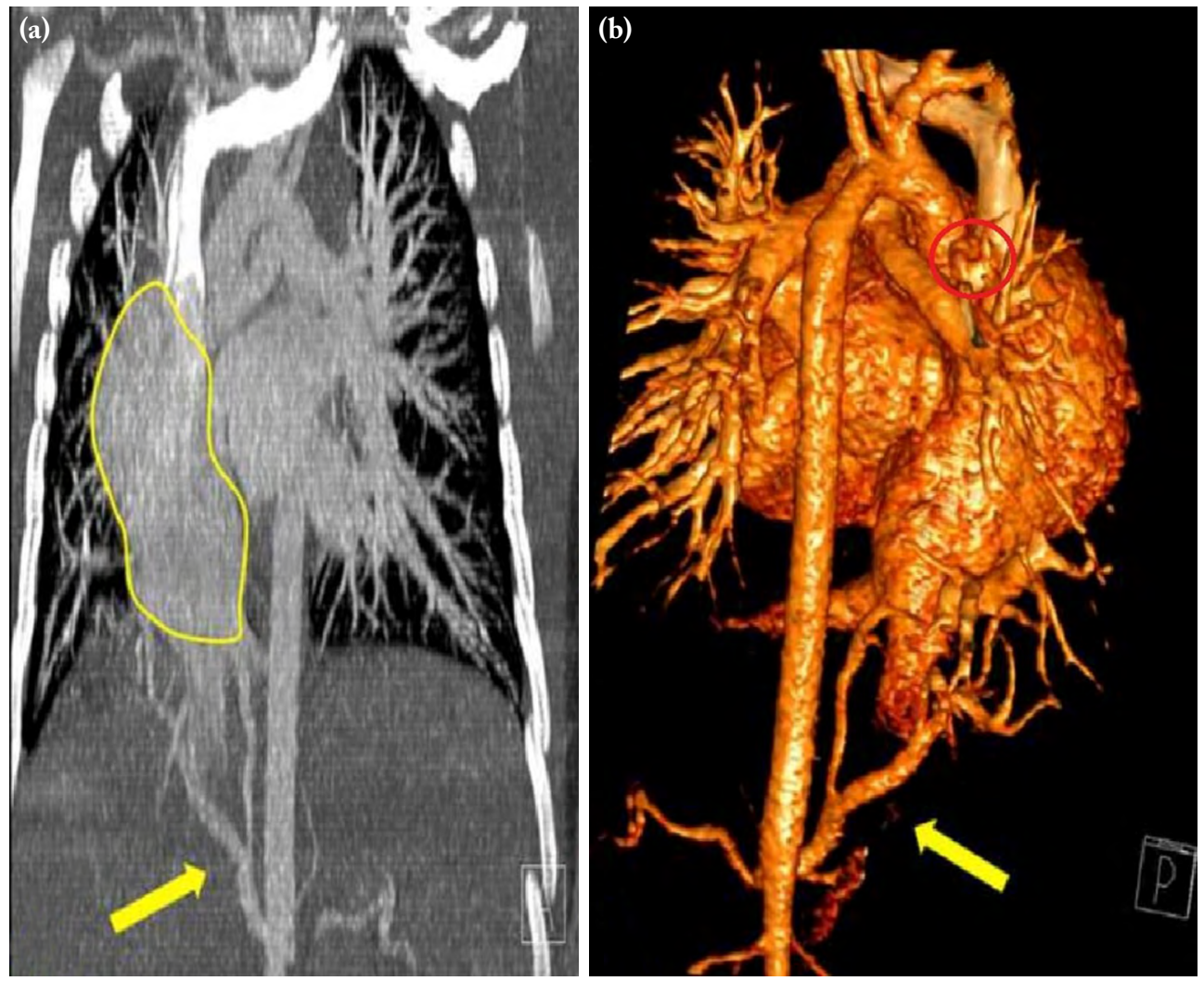

Figure 1. (a) Computed tomography image showing sequestrated pulmonary segment. Arterial branches originating from celiac trunk were marked with yellow arrow. (b) Three-dimensional image: Arterial branches originating from celiac trunk were marked with yellow arrow and abnormal venous connection was circled. 


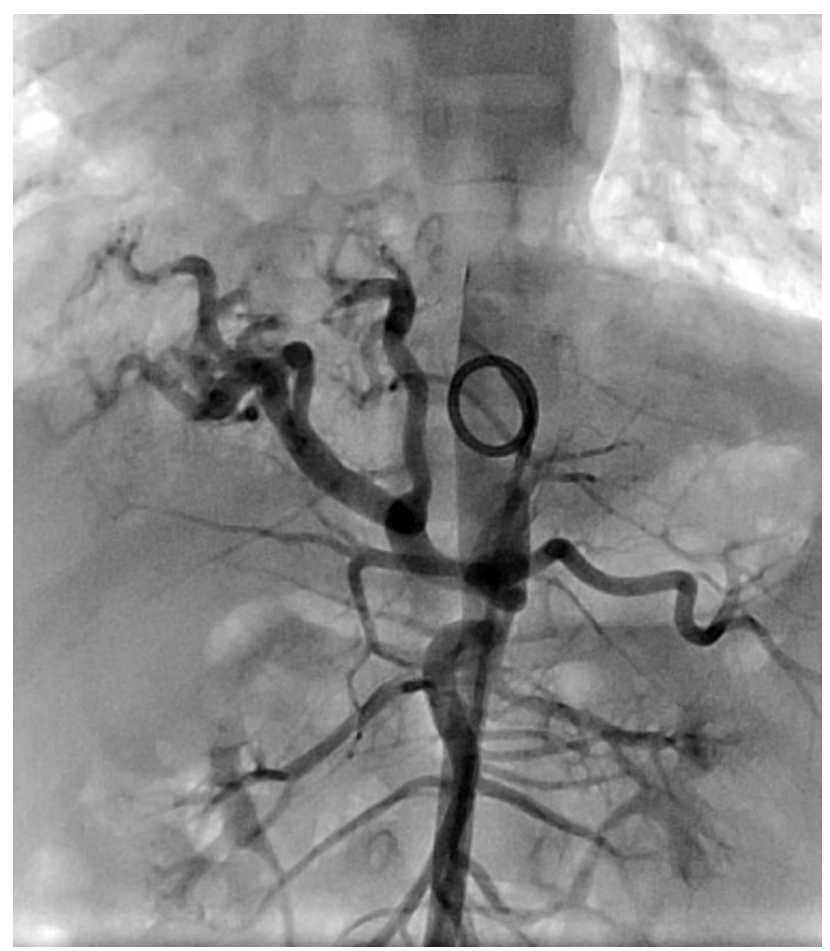

Figure 2. Conventional angiography image showing arteries arising from celiac trunk towards sequestrated pulmonary segment.

segment were ligated and removed. The rest of the pulmonary tissue was stitched with Vicryl (Ethicon Inc., Somerville, NJ, USA) by running suture technique to avoid air leakage.

The patient was admitted to intensive care unit (ICU). Neither positive inotrope infusion nor blood product replacement was needed postoperatively. The patient was extubated at the fourth hour in the ICU. The regular venous blood gas samples showed only a moderate elevation in partial carbon dioxide value, which was measured between $45-50 \mathrm{mmHg}$. Nonetheless, the patient was suffering from dyspnea. The pediatric consultation edited the inhaler therapy and nutrition. Postoperative X-ray chest radiography and TTE were uneventful. In postoperative day two, the patient was transferred to pediatric ICU. Thereafter, in postoperative day four, the patient was taken into ward without any respiratory symptoms and discharged at postoperative day seven.

\section{DISCUSSION}

Both PAPVC with intact interatrial septum and PS are rare congenital disorders. When separately considered, although both diseases are not often, they have been treated successfully in our clinic for years. ${ }^{[7,8]}$ However, in this case, some points were controversial about the surgical planning hence a multidisciplinary assessment was necessary. Indications for PAPVC with intact septum do not differ from solely PAPVC cases. The authors recommend performing surgery when pulmonary to systemic flow rate is above 2 .

As usual, in cases of PAPVC associated with intact septum, an intraatrial pericardial patch tunnel is often utilized. ${ }^{[7]}$ The mediastinal access can be provided via a full or partial median sternotomy or a right anteolateral thoracotomy.

On the other side, PS requires a different surgical notion. Mostly, PS does not require surgical resection until the condition becomes complicated. Nevertheless, if surgery is decided, resection of only the sequestrated segment will be enough since the ILS is surrounded by normal lung tissues. Open thoracotomy remains the best option with safe isolation, providing an optimal visualization and division of anomalous systemic feeding arteries. ${ }^{[8]}$ However, in our case, the anomalous systemic arterial supply was maintained via a branch of celiac trunk contrary to the majority of thoracic arterial sources.

Particularly when the surgeons do not have an adequate experience in the presence of such combined diseases, each step regarding the surgical process should be thoroughly planned preoperatively. Here, one of the main issues was whether or not to perform the ILS resection under a cardiopulmonary bypass (CPB). Cardiopulmonary bypass involves some advantages such as aspirating and supplying blood return towards systemic circulation in case of vascular damage during operation process. Nonetheless, elongated CPB time has well known disadvantages. Thus, the pediatric surgeons decided to perform ILS resection without $\mathrm{CPB}$ to avoid the possible harmful effects through the same median sternotomy incision although they had never experienced this approach before.

To summarize, we presented a case with partial abnormal pulmonary venous connection with intact interatrial septum and right lower pulmonary lobe sequestration which were treated in a single stage via median sternotomy. Both are rare congenital diseases and hard to diagnose in asymptomatic children. However, when surgical treatment is essential, a medical council should evaluate the patient profoundly and decide on how to perform each step of the surgical process. 


\section{Declaration of conflicting interests}

The authors declared no conflicts of interest with respect to the authorship and/or publication of this article.

\section{Funding}

The authors received no financial support for the research and/or authorship of this article.

\section{REFERENCES}

1. Alpert JS, Dexter L, Vieweg WV, Haynes FW, Dalen JE. Anomalous pulmonary venous return with intact atrial septum: diagnosis and pathophysiology. Circulation 1977;56:870-5.

2. Stewart JR, Schaff HV, Fortuin NJ, Brawley RK. Partial anomalous pulmonary venous return with intact atrial septum: report of four cases. Thorax 1983;38:859-62.

3. Atik E, Bhering MA, Assad RS. Partial anomalous return of four pulmonary veins with intact interatrial septum defect. A rare case report. Arq Bras Cardiol 2008;91:e1-3.

4. Kim YN, Cho HJ, Cho YK, Ma JS. Partial anomalous pulmonary venous connection with intact atrial septum in a child with ventricular septal defect: a case report. Korean J Pediatr 2012;55:24-8.

5. Gezer S, Taştepe I, Sirmali M, Findik G, Türüt H, Kaya $S$, et al. Pulmonary sequestration: a single-institutional series composed of 27 cases. J Thorac Cardiovasc Surg 2007;133:955-9.

6. Wani SA, Mufti GN, Bhat NA, Baba AA. Pulmonary sequestration: early diagnosis and management. Case Rep Pediatr 2015;2015:454860.

7. Işı1k O, Baş T, Koç M, Aydın H, Kutsal A. Parsiyel anormal pulmoner venöz dönüş anomalisi ile intakt atrial septum birlikteliği: Nadir bir konjenital anomali. Ege Tıp Dergisi 2015;54:144-2.

8. Ceylan KC, Öztürk T, Usluer O, Başok O. İntralober akciğer sekestrasyonu. Ege Tip Dergisi 2008;47:201-2. 